18 Cardozo LD, Cooper DJ, Versi E. Oxybutynin chloride in the management of detrusor instability. Neurourology and Urodynamics 1987;6:256-7.

20 Moore $\mathrm{KH}$, Hay DM, Imrie AE, Watson A, Goldstein M Oxybutynin hydrochloride $(3 \mathrm{mg})$ in the treatment of women with idiopathic detruso hydrochlonde (3 mg) in the treatment
instability. Br f Urol 1990;66:479-85.

22 Ramsden PD, Hindmarsh JR, Price DA, Yeates WK, Bowditch JD. DDAVP for adult enuresis-a preliminary report. Brf Urol 1982;54:256-8.

23 Hilton P, Stanton SL. The use of desmopressin (DDAVP) in nocturnal urinary frequency in the female. $\mathrm{Br} \mathcal{F}$ Urol 1982;54:252-5.

24 Knudsen UB, Rittig S, Pedersen JB, Norgaard JP, Djaarhus JC. Long term treatment of nocturnal enuresis with desmopressin-influence on urinary output and haematological parameters. Neurourology and Urodynamic 1989;8:348-9.

25 Fantl JA, Wyman JF, Anderson RL, Matt DW, Bump RC. Postmenopausa urinary incontinence: comparison between non-estrogen supplemented and estrogen supplemented women. Obstet Gynecol 1988;71:823-8.

26 Blackford W, Murray K, Stephenson TP, Mundy AR. Results of transvesical infiltration of the pelvis with phenol in 116 patients. $B r f$ Urol 1984:56: 647-9.

27 Rosenbaum TP, Shah PJR, Worth PHL. Transtrigonal phenol: the end of an era? Neurology and Urodynamics 1988;7:294-5.

28 Wall LL, Stanton S. Transvesical phenol injection of pelvic nerve plexuses in females with refractory urge incontinence. Br $\mathcal{F}$ Urol 1989;63:465-8.

29 Bramble FJ. The treatment of adult enuresis and urge incontinence by enterocystoplasty. Brf Urol 1982;54:693-6.

30 Mundy AR, Stephenson TP. "Clam" ileocystoplasty for the treatment of refractory urge incontinence. Br $\mathcal{O}$ Urol 1985;57:641-6.

31 Karam MM, Bhatia NN. Management of coexistent stress and urge incontinence. Obstet Gynecol 1989;73:4-7.

32 Rosenbaum TP. The Autocath. A new concept to facilitate self catheterization in females. Urogynaecologia 1990;IV:134.

(Accepted 15 May 1991)

\title{
Medicine in Europe
}

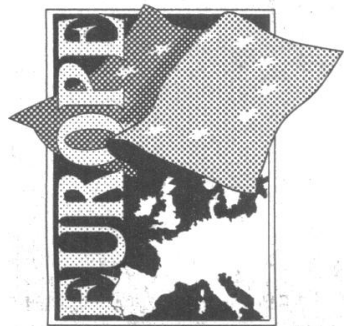

This is the third of a series of articles looking at medical issues in Europe.

\section{European health care systems}

Tony Smith

Every European country is worried about the cost of health care, and most are looking for ways of reorganising their health systems in the hope of reducing costs (see box).

In the 1970s and early 1980s expenditure on health rose faster than the growth in the economy in almost all countries in the Organisation for Economic Cooperation and Development (the OECD includes not only the countries of western Europe but also Japan, the United States, Canada, and Australia). The reasons are familiar enough. Firstly, in all these countries the proportion of old people in the population has been rising, and old people are the main consumers of health care. Secondly, technical and pharmaceutical in novations in health care have led to a real increase in demand for procedures such as joint replacement and for expensive drugs such as erythropoietin. This differential increase in health expenditure is commonly expressed as a ratio, known as the elasticity, between growth in expenditure per citizen on health and the per capita growth in the country's gross domestic product (GDP). Between 1975 and 1987 the average elasticity in OECD countries was $1 \cdot 1$-indicating that health spending was growing at a $10 \%$ faster rate than the
GDP. The elasticities ranged from 0.9 in Denmark and 1.1 in the United Kingdom to 1.3 in the United States, Belgium, and Japan. Since 1987 economic recession has led to slower growth rates in GDP and the elasticity ratio has widened. In some European countriesGermany and Sweden-expenditure on health has declined in the past three years as a proportion of GDP (see table) while in other countries it has levelled off.

\section{Basic models}

Just as every unhappy family is unhappy in its own way so each country in the OECD has evolved a unique health care system, each of which is unsatisfactory in some respects. The main division between health systems is whether they are funded primarily from taxation (as in Britain, Denmark, Italy, and Sweden) or from some form of social insurance (as in Belgium, France, Germany, the Netherlands, and Greece).

Social insurance for health was introduced in Germany under Bismarck, and in those countries which use the system enrolment in an insurance scheme is usually obligatory for all low paid workers. Usually the contributions made by workers cover
British Medical Journal, London WC1H 9JR

Tony Smith, MB, associate editor

BMf 1991;303:1457-9

\section{Current proposals for modification to health care in European countries}

Britain is by no means alone in going through a period of rapid change in the system of health care. Most of our European neighbours are looking for ways of making their systems more efficient - or at least for ways of slowing the apparently remorseless rise in costs. Some of these proposals were discussed at a conference in Brussels in June 1991; among the talking points were the following.

France has seen spending on health accelerate far beyond the annual rise in GDP and is looking for ways of reducing its overcapacity. There is talk of cutting the number of general practitioners by 20000 and of substantial cuts in numbers of hospital beds. As immediate measures public hospitals have been given overall budgets with cash limits and the payments required from patients have been increased. Other proposals include a revised system of reimbursements based on the American concept of diagnosis related groups.

The Netherlands attempted in 1988 to introduce system of regulated competition among insurance companies and among providers of health care. Individual citizens will get a subsidy to help them buy health insurance (which will remain compulsory). The subsidy will come from a central fund dependent on premiums paid by the tax collector. The competing insurance companies will offer different packages of benefits. The target date for the implementation of these proposals was originally set as 1992 , but it has now been postponed to 1995

The Germans are currently most concerned to find ways of integrating the inhabitants of eastern Germany into the existing, very expensive, health care system

In Greece there has been growing recognition of what is termed the "access trap" - the standards of care provided by many of the sickness funds are inadequate, but the private services are too expensive for most people. Greek health care for most people is based on a black economy in which patients make illegal payments to doctors to top up the doctors' inadequate salaries and reimbursement fees. This black economy is said to amount to $2 \%$ of the GDP. According to one speaker at the Brussels conference there is "a labyrinth of institutions, standards, and interests but no plans - only a lot of disillusion."

Spain is making slow progress towards introducing universal coverage through multiple financing; this will be based on a health insurance system that will require substantial contributions from employers. 
Health expenditure in selected European countries and United States. Figures are US dollars (percentage of GDP)

\begin{tabular}{lrrr}
\hline & 1970 & 1980 & \multicolumn{1}{c}{1989} \\
\hline Belgium & $123(4 \cdot 1)$ & $513(6 \cdot 3)$ & $980(7 \cdot 2)$ \\
Denmark & $209(6 \cdot 1)$ & $571(6 \cdot 8)$ & $912(6 \cdot 3)$ \\
France & $192(5 \cdot 8)$ & $656(7 \cdot 6)$ & $1274(8 \cdot 7)$ \\
Germany & $199(5 \cdot 9)$ & $749(8 \cdot 5)$ & $1232(8 \cdot 2)$ \\
Greece & $62(4 \cdot 0)$ & $196(4 \cdot 3)$ & $371(5 \cdot 1)$ \\
Netherlands & $207(6 \cdot 0)$ & $707(8 \cdot 2)$ & $1135(8 \cdot 3)$ \\
Sweden & $274(7 \cdot 2)$ & $864(9 \cdot 5)$ & $1361(8 \cdot 8)$ \\
United Kingdom & $146(4 \cdot 5)$ & $454(5 \cdot 8)$ & $836(5 \cdot 8)$ \\
United States & $346(7 \cdot 4)$ & $1059(9 \cdot 3)$ & $2354(11 \cdot 8)$ \\
\hline
\end{tabular}

themselves and their family and vary with income, so that the better paid subsidise the less well paid and the young and single subsidise the elderly and those with large families. In some countries, such as France and Germany, the contributions to the schemes are shared between the employee and the employer: for example, the weekly contribution of car workers in Germany is $6 \%$ of their earnings and the employers pay in a further $6 \%$ on their behalf.

Higher earners may choose to pay higher premiums into alternative insurance plans that offer wider or more generous benefits. The elderly, the unemployed, and chronic sick are included in the basic insurance schemes, their contributions being paid by the state. In striking contrast with the United States, all countries in the European Economic Community have accepted for many years the principle of provision of health care as of right for the whole population.

In countries with social insurance schemes there may be few or many insurance plans. Often there are a few large non-profit health funds and a larger number of "private," for profit schemes. France has three main sickness funds-for salaried employees, for farmers and agricultural workers, and for the self employed. In Belgium the many mutual aid societies have religious and political affiliations. In theory the existence of multiple schemes encourages competition, but in practice the choice open to an individual worker may be fairly small. Higher paid people do, however, have a wider choice in most countries with insurance based health care.

Insurance based health care is not, however, an example of a free market in health: in all these countries the government exerts some control over the running of the schemes and in most it plays a major part in determining the premiums paid by workers and the fees paid by the schemes to doctors and to hospitals. Typically there is some sort of annual negotiation among all the parties-government,

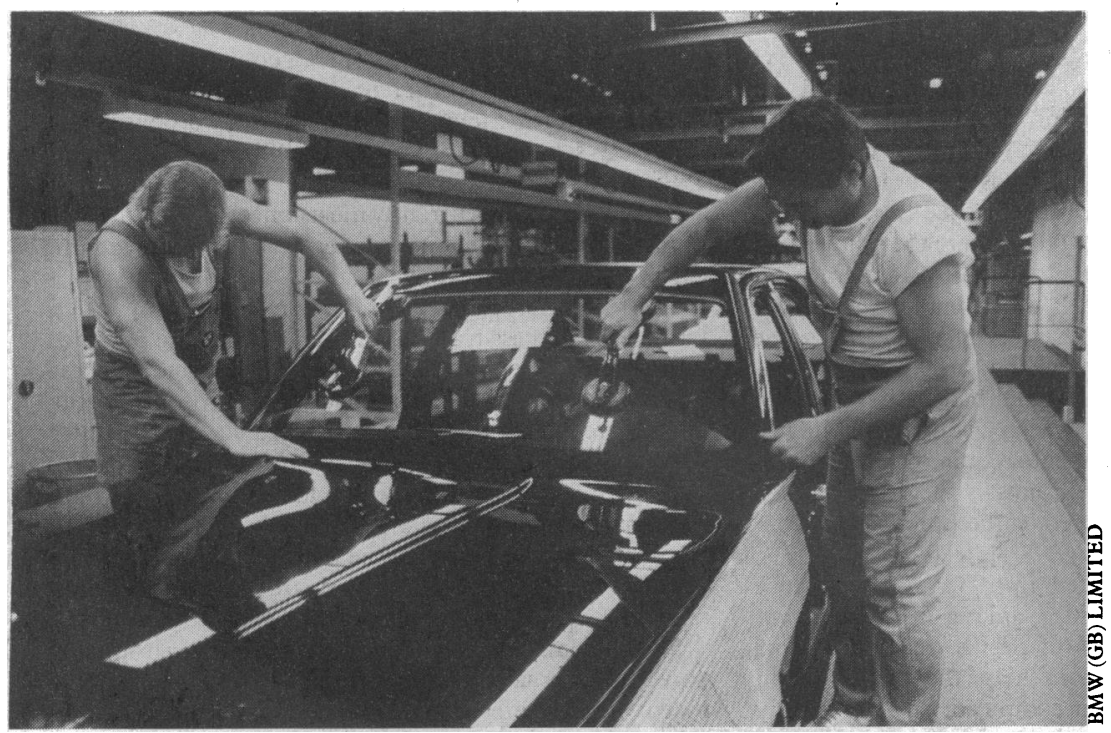

Car workers in Germany contribute 6\% of earnings for health insurance; their employers pay in another 6\% on their behalf sickness funds, private insurers, hospitals, and medical associations - at which the premiums and benefits for the next year are agreed.

\section{Patients' contributions}

Patients make some direct contribution to the costs of their care in all countries in the OECD. In some this simply takes the form of a part payment for drugs. In several insurance schemes, however, such as in Belgium and France, the patient is required to pay a contribution - which may be as much as $25 \%$ - to the cost of a consultation with a general practitioner, and contributions are also required for hospital treatment. It is possible but not obligatory for citizens to insure against these direct payments. No direct charge is usually made to the elderly, the chronic sick, or the unemployed; and prolonged illness is never expensive in the way that it may be in the United States.

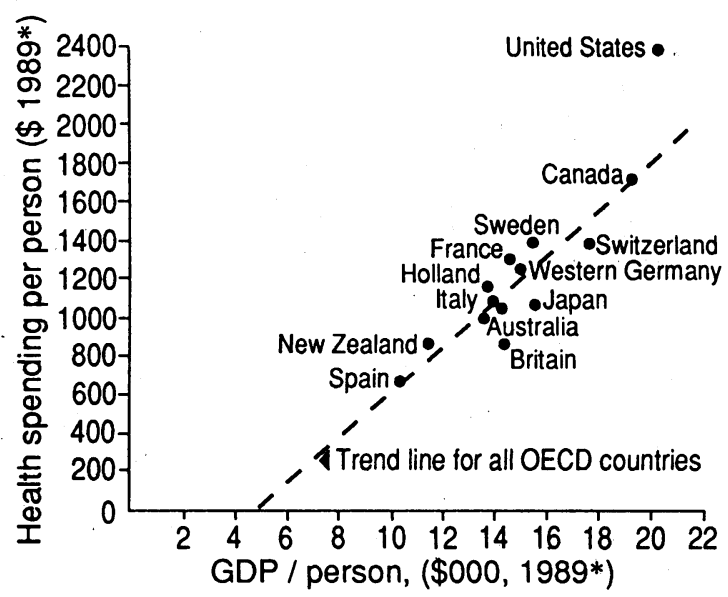

Sources: OECD; Health Care Financing Administration * Converted at purchasing-power parities Health expenditure in OECD countries in US dollars and as proportion of gross domestic product

\section{Payments and fees}

The ways in which doctors and hospitals are paid for the work they do also vary widely. Doctors working outside hospitals usually own the premises from which they practice or rent space in a health centre. Hospitals are owned and run almost exclusively by the state or by local government in most of the Scandinavian countries. Elsewhere in Europe some hospitals are state owned, some are run for profit by private companies, some are run by non-profit corporations, and some are owned and run by the insurance companies themselves. The proportion of hospitals owned and run by the state ranges from $50 \%$ in Germany, $66 \%$ in France, and $85 \%$ in the Netherlands to virtually $100 \%$ in Sweden - though even in that temple of socialism there are a few private nursing homes.

The hospitals and the medical staff working in them may, as in Britain and Scandinavia, be financed from taxation, with the doctors earning salaries. In insurance based systems there is usually some link between payment and the work done, with the insurance funds paying either a daily rate or on an item of service basis. Some of the systems are of Byzantine complexity. In Germany, for example, under the statutory health insurance scheme "neither the patient nor the doctor knows at the time of treatment the exact amount that the doctor will be paid. The patient, moreover, will never know. The doctor will receive payment later through his professional association on the basis of an agreed nomenclature of services and in accordance with a scale of fees worked out on the basis of the forecast overall budget agreed by the funds and 
apportioned among the physicians within a region in relation to their workload."

Doctors in general practice may be salaried, paid on a capitation basis, or paid per item of service or per patient treated - or they may be paid by a combination of these methods. In the Netherlands, for example, the health insurance schemes fix an earnings target for general practitioners and calculate the capitation payment to provide $70 \%$ of this target. The assumption is that each doctor will earn the remaining $30 \%$ of the target from private practice, for which payment is made on an item of service basis.

\section{Actual health expenditure}

The most widely used measures of health expenditure are the amount spent per person expressed in US dollars and the amount spent per person as a fraction of GDP (figure). ${ }^{2}$ Neither measure gives a true picture of differences between countries in the health care delivered to the patient. Factors that also have to be taken into account include the expectations of and the demand by patients, how well doctors and other health workers are paid relative to the rest of the population, and the overall efficiency of the system-one recent estimate suggested that nearly a quarter of the expenditure on health care in the United States went on administrative costs.

What these measures do provide is some guidance on changes within and between countries. The past $?$ two decades have seen substantial growth in health $\vec{F}$ expenditure in all countries with the exception of those $\stackrel{5}{+}$ in Scandinavia, which has pulled back a little towards the average in the European Community. Health expenditure has grown in Britain, but the rate of growth has been slow compared with most of our $\stackrel{\mathbb{Q}}{\varrho}$ neighbours; our overall expenditure is still near the in bottom of the table.

1 Sandier S. Health services utilisation and physician income trends. Health Care Financing Review 1989;suppl:33-47.

2 Schieber GJ, Poullier J-P. International health spending: issues and trends. Health Affairs 1991 Spring:106-16.

\section{Health and the Environment}

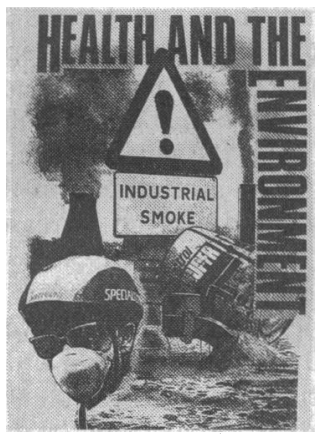

\section{Air pollution: I-From pea souper to photochemical smog}

\section{Fiona Godlee}

Air pollution has changed since the infamous winter fog of 1952 that killed 4000 Londoners. ${ }^{1}$ Instead of the localised but lethal accumulation of sulphurous fumes -caused when large amounts of smoke from coal fires coincided with winter anticyclones (box)-the industrialised world now spends the summer draped in a photochemical haze of vehicle exhaust. Photochemical smog is, in its way, no less dangerous to health than the old winter fogs. There is increasing recognition of the role of smog in acute and chronic cardiorespiratory disease. But winter fogs, too, continue to take their toll. In the West clean air legislation has made them a thing of the past. But in eastern Europe and the Third World sulphurous pollution remains a major threat to health.

\section{Sulphurous pollution}

The World Health Organisation estimates that nearly 625 million people around the world are exposed to unhealthy levels of sulphur dioxide, and more than a billion people-one in five of the world's populationto excessive levels of particulate pollution. ${ }^{2}$ Sulphur dioxide and particulates such as soot are the main airborne products from burning high sulphur fuel. Given the right meteorological conditions-cold, moist air - and the presence of certain metal catalysts in polluted droplets of water - they combine to form aerosols of sulphuric acid. Easily inhaled into the lungs, this is probably the component of winter pollution that causes most damage to health. ${ }^{3}$

Pollution derived from high sulphur fuel has been linked with chronic bronchitis in adults and chest infections in children since the $1940 \mathrm{~s}$, though some studies have found no clear association. ${ }^{4}$ In one study patients with bronchitis had significant exacerbations when concentrations of black smoke and sulphur dioxide in the air exceeded $250 \mu \mathrm{g} / \mathrm{m}^{3}$ and $500 \mu \mathrm{g} / \mathrm{m}^{3}$ respectively. ${ }^{5} \mathrm{~A}$ study in Sheffield found an increase in both upper and lower respiratory tract infection in children living in heavily polluted areas. ${ }^{6}$

More recently, despite a fall in pollution from high

\section{Winter fogs}

The dangers of sulphurous pollution were most dramatically illustrated in December 1952 when a dense fog covered London killing up to 4000 people (fig 1). Other industrial cities had suffered similar, though less severe, episodes. Glasgow experienced two severe fogs in the winter of 1909 , and another in 1925 , all accompanied by an increase in mortality. In December 1930, five days of polluted fog killed more than 60 people in Belgium's industrial Meuse valley; and in Donora, Pennsylvania, 18 people died because of polluted fog during a two week period in October 1948.

These pea souper fogs depended as much on meteorological conditions as on emissions of sulphur dioxide and soot. The anticyclone that settled over London on 5 December 1952 heralded a rare period of calm weather. Temperature inversion - a cold layer of air at ground level overlayed by a zone of warmer air - prevented the air from circulating and allowed the build up of emissions from low lying industrial and domestic chimneys. The trapped emissions combined with moisture in the cold air to form a deadly fog of acid vapour and black smoke.

Concentrations of sulphur dioxide reached a peak of nearly $4000 \mu \mathrm{g} / \mathrm{m}^{3}$-more than 10 times the maximum level set down by the World Health Organisation as safe to breathe for one hour. ${ }^{2}$ The victims-mostly young children and people over 65-died of heart and lung disease. In the week after the fog, sickness claims doubled and admissions to hospital rose from a daily average of 750 to 1110 . Ammonia bottles with wicks brought the only relief from bronchial irritation, bronchospasm, dyspnoea, and cyanosis caused by the acidic air.

sulphur fuels, ${ }^{2}$ studies in various countries have shown $\stackrel{\varnothing}{\varnothing}$ an association between acid aerosols and morbidity and mortality, especially among people with asthma (D V 8 Bates, meeting of the British Thoracic Society, Birmingham, 13 July 1990). Outcome measures affected by concentrations of sulphur dioxide and sulphates include increased absenteeism from work, ? respiratory symptoms in children, ${ }^{8}$ lowered forced expiratory volume in one second, ${ }^{9}$ increased emergency 